Article

\title{
Newsworthiness as a Governing Principle in Public Sector Communication
}

\author{
Maria Grafström * and Hanna Sofia Rehnberg \\ Stockholm Centre for Organizational Research, Stockholm University, Sweden \\ * Corresponding author (maria.grafstrom@score.su.se)
}

Submitted: 21 April 2021 | Accepted: 13 October 2021 | Published: 20 January 2022

\begin{abstract}
This article examines what qualifies as news when public agencies in Sweden claim to engage in media work. We unwrap and explore what happens when ideas about "newsworthiness" enter the practice of public sector communication. What becomes news, and how? What kinds of content are favored, how are stories told, and what voices are heard? The ideas of newsworthiness in a public sector context are here conceptualized as a logic of appropriateness that governs civil servants' media work. We base our analysis on a three-year case study of a Swedish county council's digital news channel, VGRfokus. The analysis focuses on how ideas of newsworthiness are constructed and mirrored in and through the content of VGRfokus, as well as how they are reflected and acted upon by communications professionals working at the news channel. We suggest that ideas of newsworthiness may function as a governing principle and tone down or even hide conflicts and tensions between key values of bureaucracy and market, otherwise often manifested in public sector communication.
\end{abstract}

\section{Keywords}

bureaucratic values; civic information; digital news channel; logic of appropriateness; market values; newsworthiness; public sector communication; media work; strategic communication; VGRfokus

Issue

This article is part of the issue "New Forms of Media Work and its Organizational and Institutional Conditions" edited by Salla-Maaria Laaksonen (University of Helsinki) and Mikko Villi (University of Jyväskylä).

(C) 2022 by the author(s); licensee Cogitatio (Lisbon, Portugal). This article is licensed under a Creative Commons Attribution 4.0 International License (CC BY).

\section{Introduction}

"No one owns the concept of news" ("Kommun startar egen 'nyhetsförmedling,'" 2019). The comment was made in 2019 by a Swedish municipality to explain and justify the initiative to start a news service. Five years earlier, the communications director of another Swedish municipality had stated that their goal was to be "the leading news source" in the community ("Kalix bygger nyhetsredaktion," 2014). And yet another municipal communications manager explained in the magazine Dagens Samhälle (Sundling, 2015) that "the media have no monopoly on telling the story of what is happening in [the city of] Gävle." These quotes, collected from different newspaper articles, are prompted by tensions created by the ongoing trend to reorganize parts of public sector communication in the form of news production (cf. Grafström \& Rehnberg, 2019; Rehnberg \&
Grafström, 2021). This reorganization, we argue, can be understood as civil servants, often with a background in journalism, engaging in "media work" and producing "media-like content" (cf. Deuze, 2009).

In this article, our aim is to develop insights into how the use of journalistic methods and formats influence public sector communication. We are particularly interested in unwrapping and exploring what happens when ideas about newsworthiness enter the practice of public communication. What becomes news, and how? What kinds of content are favored, how are stories told, and what voices are heard? In this analysis, we conceptualize ideas of newsworthiness as a "logic of appropriateness" that governs actors' behavior (March \& Olsen, 2011). Consequently, we are not interested in newsworthiness in terms of journalistic ideals. Instead, we strive to understand what communications professionals perceive as news in the context of public sector communication. 
The perspective allows us to reflect upon how ideas of newsworthiness in a public sector context relate to both traditional bureaucratic values, stressing factuality, openness, and equal treatment, and to more recent market values emphasizing results, efficiency, and competition.

While previous studies have shown how public agencies engage in proactive media management through the pitching of news stories to selected journalists in order to create positive media images and counteract critical media coverage (Figenschou et al., 2021; Figenschou \& Thorbjörnsrud, 2015), our study places the focus on a different type of proactive communication work: the establishment of a news channel. Our ambition is to contribute with an understanding of how ideas of newsworthiness are reflected and acted upon by communications professionals in a public sector context permeated by values of bureaucracy and market. Our study thereby corresponds with recent calls to develop more knowledge both on what shapes norms and practices in public sector communication (cf. Jacobs \& Wonneberger, 2019) and on how diverse and incompatible values are manifested and given meaning in such processes (Fredriksson \& Pallas, 2016).

We base our analysis on a three-year case study of the digital communication channel VGRfokus, which was launched as a news channel in November 2017 by a county council on the west coast of Sweden, Region Västra Götaland (VGR). The articulated goal is to provide journalists, employees, and citizens in the region with up-to-date information, and it is explicitly stated that this goal is to be achieved through the use of journalistic working methods and formats.

\section{Institutional Environment, Values, and Logic of Appropriateness}

To situate our study object in an institutional environment, we present two values characterizing the public sector-bureaucratic values and market values-and focus specifically on how these values condition public sector communication. In order to capture how journalistic methods and formats influence public sector communication and its output, we conceptualize ideas of newsworthiness as a logic of appropriateness.

\subsection{Bureaucratic Versus Market Values in Public Sector Communication}

The institutional environment of the public sector is characterized by complex and pluralistic conditions that make the communication work different from, for example, that of corporations and civil society. An institutional perspective also challenges and stands in contrast to "self-interested and rationally calculating actors, instrumentalism, and consequentialism" (March \& Olsen, 2011 , p. 3). Human behavior instead needs to be understood as embedded in and governed by values, norms, and rules. The public sector is expected to uphold bureaucratic values, such as factuality, transparency, equal treatment, impartiality, neutrality, loyalty, correctness, and accountability (e.g., Christensen et al., 2007). In recent decades, the influence of the corporate world has brought in a different set of values rooted in market ideology (e.g., Hood, 1991). This has spurred, motivated, and intensified the adoption and use of models and ideas from the private sector, emphasizing, for example, results-based management, efficiency, performance measures, and competition.

Bureaucratic and market values will therefore make different types of practices appear as appropriate and legitimate in all parts of the public sector, and the communication work is no exception. Briefly, this means that values with roots in bureaucratic and public administration prescribe that civil servants inform citizens in formats that are easily accessible, and secure that public documents are made available when asked for (Figenschou et al., 2021; cf. Fredriksson \& Pallas, 2016).

Values stemming from the corporate sector, in contrast, direct civil servants to engage in strategic communication (Figenschou et al., 2021), with a focus on branding (Wæraas, 2008), reputation management (Byrkjeflot, 2015), media management (Figenschou \& Thorbjörnsrud, 2018), and crisis communication (Heide \& Simonsson, 2015). The strengthened presence of market values has also motivated new forms of assignments and increasingly central positions for publicly employed communicators (Kolltveit \& Figenschou, 2020).

Previous studies show that ideas of branding and reputation inscribed in strategic communication create tensions and paradoxes for civil servants in general and not least for public sector communicators, since these ideas are often in direct conflict with key values of bureaucracy. In an analysis of communication policy and strategy documents in Swedish public agencies, Fredriksson and Edwards (2019) identify tensions centered around the ideas of transparency and consistency. Similarly, in their studies of Swedish hospitals, Blomgren et al. (2015) show how reputation management and strategic communication activities, traditionally characterized by an emphasis on coherency, are not easily combined with the inconsistencies and contradictions of public organizations.

\subsection{Newsworthiness as a Logic of Appropriateness in the Public Sector}

In order to analyze how journalistic methods and formats influence media work in a public sector context, we conceptualize ideas of newsworthiness as a logic of appropriateness. When civil servants, or other actor groups, act "appropriately," they "proceed according to the institutionalized practices of a collectivity, based on mutual, and often tacit understandings of what is true, reasonable, natural, right, and good" (March \& Olsen, 2011 , p. 2). We argue that when journalistic methods and formats are adopted by civil servants, ideas of newsworthiness are manifested and developed, and these 
ideas have the potential to influence what is understood as appropriate content and formats of public sector communication. In this way, ideas of newsworthiness bear the potential to strengthen or challenge existing norms and routines of public sector communication practices.

News does not mirror reality, and news-making processes are structured according to certain criteria for what is considered newsworthy (Harcup \& O'Neill, 2017). These are rooted in journalistic values, such as public service, neutrality, credibility, and ethics (Deuze, 2005). These values overlap and go well together with traditional bureaucratic values. Yet there are also values more exclusive to journalism, mainly independence and immediacy (Deuze, 2005), the value of standing with the individual against the powerful (Aare, 2021), and the high regard for scrutiny. It might even be reasonable to say that scrutiny forms the basis for the other journalistic core values, the soil from which they draw nourishment, especially in a Nordic context (Ahva et al., 2017). In line with the values of scrutiny, journalism is accorded considerable democratic significance (e.g., Figenschou \& Thorbjörnsrud, 2015; Wiik, 2008).

News is, in the words of Schudson (2003, p. 33), "a representation of the world, and all representations are selective." Events are not out there ready for journalists-or others, such as communications professionals - to pick up and forward as news. News-making processes are shaped by multiple factors that include everything from journalists' normative ideas on the news value of potential stories to practical, economic, and format considerations (Strömbäck et al., 2012). There is no shortage of lists of criteria for newsworthiness (in the form of event properties) in journalism studies, including aspects such as closeness to the audience in time and space, references to elite persons, something negative, conflict-related, extraordinary, or entertaining (Harcup \& O'Neill, 2017; Strömbäck, 2019). Newsworthiness may also be created through the use of different storytelling techniques, such as simplification, polarization, dramatization, and stereotypization (e.g., Rehnberg, 2014; Strömbäck, 2019). The result is that news stories tend to be relatively short and episodic, focus on a single event, and favor unambiguity (Figenschou \& Thorbjörnsrud, 2015); they also need human faces, both as illustrations and in order to attract attention (Figenschou \& Thorbjörnsrud, 2018; Thorbjørnsrud \& Ytreberg, 2020).

\section{Method and Material}

In order to develop an understanding of how ideas of newsworthiness may influence the content of media work in the public sector, we chose a case study design and combined multiple data sources: the content of VGRfokus, interviews, meeting observations, and official documents. The combination of data sources allows for different pictures and views to emerge, which should be seen as supplementary (Czarniawska, 1998). This, in turn, allowed us to not only investigate the meaning and influence of newsworthiness in a public sector context but to also elaborate a problematized understanding of rationales behind the use of journalistic methods and formats in this specific context and to conduct a deeper and more profoundly contextualized discussion of outcomes in terms of news content.

\subsection{VGRfokus as our Case}

We actively searched for a case in which civil servants themselves presented their communication work as news production and claimed to use journalistic methods. Over the last few years, in the Swedish context, we have witnessed an increased number of such cases in which organizations (both private and public) reorganize part of their communication work in order to resemble news desks, and actively appropriate methods and rhetoric from journalism (e.g., Ekengren, 2018).

Our selection of the digital communication channel VGRfokus, which primarily includes online news articles (sometimes with the additional content of a few videos and Facebook posts), is motivated by the rather farreaching journalistic ambitions characterizing the news channel and the work behind it. The channel, which is operated by the Swedish county council VGR, received quite a lot of media attention when it was launched in November 2017. It aims to be VGR's main channel for news related to the county council's core tasks, which are mainly health care, but also public transport and culture as well as trade and industry. With about 53,000 employees, VGR is one of the largest employers in Sweden. VGRfokus aims to be a trustworthy channel with news value, targeting VGR employees, legacy media, citizens, and other interest groups (Lagersten, 2017). The VGRfokus staff belong to the press team at VGR's department of communications and public affairs, and VGR's communications director is also the publisher. The two civil servants (referred to as editors) responsible for the day-to-day practical work with VGRfokus both have a professional background in journalism.

The layout of the VGRfokus website strongly resembles legacy media. For example, the content is categorized into themes, as is common on traditional media websites. When VGRfokus was launched, the communications director wrote an editorial, hereinafter referred to as "the launching text," which motivated, and marketed the VGRfokus initiative using a journalistic vocabulary (Lagersten, 2017). We show in an analysis of VGRfokus presented elsewhere (Rehnberg \& Grafström, 2021) that many key professional values of journalism (cf. Deuze, 2005) are explicitly ascribed to VGRfokus in the launching text. At the same time, it clearly states that VGRfokus is not journalism and will not engage in scrutiny, since "a public sector agency cannot scrutinize itself; that is a task for journalists" (Lagersten, 2017). 


\subsection{Developing the VGRfokus Case With a Focus on Ideas About Newsworthiness}

In all four data types used-content, interviews, meeting observations, and official documents-we searched for criteria that reflected what was turned into news and how. In this way, each data source added to our understanding of how "newsworthiness" was interpreted by civil servants working with VGRfokus, as well as how these ideas were translated into actual article content.

To structure our empirical work, we were helped by three basic empirical questions which can be seen to cover criteria for newsworthy content:

1. What is the overall focus of the content?

2. How is the content presented?

3. Who figure in the content?

\subsubsection{Content of VGRfokus}

We collected and read all the articles (consisting of verbal texts and photos) published on the VGRfokus site during two different time periods that together total 12 months: November 2017-May 2018 and September 2019-March 2020. Our analysis indicates no major differences between the two periods, and therefore we cluster them into one set of articles. The total number of articles is 187.

To identify and develop an understanding of what issues and events are turned into news in VGRfokus, and how the news is presented, we constructed coding categories related to our three empirical questions. The question of what was captured through the coding variables "main theme" of the article and representations of VGR (mentions of VGR or subdivisions of VGR; how VGR is described in value terms such as "first in Sweden" and "innovative"). For each article, we also made notations about what seemed to have motivated the selection and publication of the news, based on explicit markers in the text (for example, "first in Sweden"). How was captured through identifying whether the tone of the articles is negative, neutral, positive, or both negative and positive; and who was captured through identifying main or subordinate actors appearing in the articles and in which role (e.g., manager, other employees, citizen) these actors appeared. We define "main actor" as the individual who is ascribed most space and focus in the article in terms of number, length, and placements of quotations, number and placements of mentions, and number and sizes of photos. In articles where two or more individuals are ascribed roughly equal space and focus, we counted them both as subordinate actors. We also coded the use of photos in more detail, which allowed us to further analyze how individuals were presented in the articles.

The coding was conducted by us, the two authors. Initially, we each separately coded a minor sample of 10 articles, and thereafter we carefully compared and discussed this coding to secure that we had a shared under- standing of the coding scheme. Second, we continued coding all articles individually. After all the articles had been coded in two different files, we compared the coding of each article in order to resolve any disagreements. At the end of the process, one single database with the final coding was created.

\subsubsection{Interviews}

Interviews with civil servants engaged in VGRfokus were essential for us to understand how particular motives and considerations influence the media work processes and how the civil servants themselves talk about and ascribe meaning to ideas about newsworthiness in their work. The interviews also gave us insights into the staff members' understanding of successful news production and informed us about what they found challenging in their work. For example, we were able to speak with our interviewees about specific articles and to ask them about the working processes behind them. The interviews were semi-structured, as we used an interview guide with a set number of questions, but these questions were somewhat modified depending on the interviewed person and also over time as we learned more about the work at VGRfokus and could ask more specific questions.

We selected the interviewees strategically to include all key individuals involved in the news channel (initiators, managers, and editors and writers doing the actual media work). We included editorial staff, a selection of other communications professionals (from different departments at VGR, all involved in VGRfokus), and communications department managers. In total, we conducted 18 interviews with 12 civil servants (four individuals have been interviewed two or three times). The interviews were conducted during four rounds from November 2017 to June 2020. All interviews were recorded and transcribed verbatim.

\subsubsection{Meeting Observations}

To develop insights into everyday discussions about what constitutes appropriate issues and events to turn into news in VGRfokus, we made observations of planning meetings, called editorial meetings. These meetings, where the two editors of VGRfokus invite communicators from other departments of VGR to participate in order to share ideas about what to publish in the news channel, are generally held on a monthly basis. Observations were undertaken both during a physical visit to VGR in September 2019 and digitally over Skype in May and June 2020. Two of the meetings were recorded, and two transcribed. We also took detailed notes during all the meetings.

\subsubsection{Official Documents}

We have read various official documents in order to learn about VGR and the overall organization and work 
of the communication department. In our analysis of newsworthiness, we have specifically included two documents directly related to VGRfokus: one visionary text and one strategic document, namely the launching text (Lagersten, 2017) and the official documents with guidelines for VGRfokus (VGR, 2017), created by civil servants at the VGR communication department.

All quotes in the article, from VGRfokus as well as from our interviews, observations, and documents, have been translated by us from Swedish to English.

\subsection{Analysis Process}

Our analysis was undertaken in four steps. First, with the guidance of our three empirical questions about what, how, and whom, we carefully went through all the material. The VGRfokus articles were coded, and the rest of the material was read in order to identify prominent examples related to newsworthiness. In this careful review of the material, we identified a number of characteristics prominent in the VGRfokus news-making processes. Second, based on the reading of the total material and the identified characteristics, we were able to develop answers to the three questions: the focus of the VGRfokus content (what); whether the news is presented in neutral, negative, positive, or both negative and positive tones (how); and to what degree humans are included in the articles and who (in terms of roles) is given most space and focus in the articles (who). As a third step, we developed our case study narrative in which we compared and reflected upon the motives and considerations expressed by civil servants, formal statements concerning VGRfokus, and the actual content of the news channel. We also compared the ideas of newsworthiness in the media work at VGRfokus with how these same aspects tend to be treated in and by legacy media, highlighting both similarities and differences. Fourth, we searched for explicit manifestations of the two sets of values-bureaucracy oriented and market oriented-in our case study narrative, which in turn allowed us to highlight and discuss how ideas of newsworthiness are used in relation to already established public sector communication.

\section{Newsworthiness as a Governing Principle in the Production of VGRfokus}

In this section, we present and discuss the results of our case study, based on the prominent aspects related to what, how, and who identified in our material.

\subsection{What Becomes News in VGRfokus?}

In the launching text, the communications director motivated VGRfokus mainly by emphasizing a need to inform people about what is going on in the region since the citizens have a right to know how their taxes are spent. He also argued that as legacy media are diminishing, jour- nalists are not able to give a full understanding of the work of VGR (Lagersten, 2017). From this perspective, VGRfokus can be interpreted as a way to inform citizens, which is an elementary part of the mission of all public authorities. The guidelines for VGRfokus state that the content of the news channel should reflect the role that VGR plays in relation to current societal issues, and that it should be possible to publish content that "critically examines" in order to counteract one-sided coverage in legacy media (VGR, 2017b,pp. 2-3). This is further developed in terms of giving "a balanced picture by explaining causes and correlations and by making room for diverging perspectives when different opinions exist" (VGR, 2017, p. 3).

The content in VGRfokus is characterized by the following traits: It is simple and straightforward, highlighting one event or issue at a time; and it is about topics that are perceived to be of interest to many readers, that are inherently positive or easy to present in a positive manner, and that are extraordinary and spectacular. In the following, we exemplify these characteristics further.

Health care is the main area of coverage in VGRfokus, which is not surprising since health care is VGR's main responsibility and a subject that concerns and engages many readers. When legacy media cover VGR, they also focus on health care issues, according to our interviewees. The VGRfokus articles on health care often report on a successful initiative, a new service, or a specific solution to a problem. Obviously, new technology could easily qualify as news here, according to the traditional journalistic criteria of newsworthiness: it is something extraordinary and spectacular that can often be illustrated through one specific device or service, and that can (frequently) be described in terms of positive effects for patients. A related way to stress the extraordinary is to highlight occasions when VGR is "a national first," and to explicitly use terms such as "unique" and "innovative." Prominent examples include articles about new technology and different types of innovations. For example, one article is about new "super advanced" technology used at the region's university hospital, another is about how Al technology helps dentists to identify caries, and other articles are about new apps or e-services that will be useful for VGR inhabitants. A series of articles titled "The Digital Patient" describes the positive development of the digitalization of health services.

While health care is VGR's core task, the organization spans multiple areas, and, according to the communications director, VGR can be understood as a "news factory" in itself, since there are plenty of issues and events to select from and to tell the inhabitants about (Interview A, December 20, 2017). This statement is confirmed by our observations of "editorial meetings": although the participants provided many tips and came up with several ideas for possible stories, only a few were selected for publication. One interviewee, a communicator who is not a member of the editorial staff, states that it is not always easy to know what the editors 
of VGRfokus consider to be newsworthy; while she and her colleagues might think that a particular event or trend is a suitable topic for turning into news content, the editors may not agree (Interview J, June 24, 2020). Sometimes, the same interviewee explains, the ideas she brings to the editorial meetings can be turned into appropriate news content, but this often requires preparation to present them in a specific way, and to provide them with a clear news angle.

\subsection{Tone: Seeing the Good in the Bad}

The ambition to use a journalistic format in VGRfokus results in articles produced with storytelling techniques and characterized by some kind of (media) dramaturgy. This is not only a question of what to tell but also a question of how to tell it. The launching text stated that VGRfokus would not only convey good news about the region and VGR's activities but also report on difficulties and problems. Additionally, it was stressed that although civil servants in VGR could not scrutinize their own organization, they "will not be afraid to address topics that may cause conflict" (Lagersten, 2017).

The content in VGRfokus is, however, characterized by a clear tendency towards prioritizing issues and events that are positive. These include topics that do not need to be "processed" to fit into a positive news frame (for example technological innovations that can save lives) but can be reported frankly, since most people can be expected to perceive them as inherently positive. This is obviously in contrast to the legacy media tendency to favor negative issues, such as conflicts, problems, and criticism of the organizations covered. One interviewee at VGRfokus argues that since legacy media often report on problems that concern VGR, there is no need for VGRfokus to tell readers the same stories in exactly the same way (interview B, November 28, 2017). However, according to the same interviewee, VGRfokus might report on the same issue but from another perspective to give the readers a piece of information that they would not otherwise have.

The drama and the tonality in VGRfokus thus tend to highlight positive incidents (e.g., interviewing someone as part of a success story rather than someone who has run into trouble), heroes rather than villains or victims, and innovations rather than failures or problems. This means that almost all the VGRfokus articles are either neutral or positive. However, this does not mean that they all report on issues and events that most people would view as joyful or positive in some way, but rather that negative topics (such as the annual tick season and tick-borne encephalitis) or problematic issues (such as long care waiting lists) are also often framed and presented in a positive way (e.g., focusing on what VGR does to help, on a solution, or on a project initiated to create positive change).

In our interviews with representatives of VGRfokus, the ambition to construct stories not only about good things but also about more problematic issues is described as important but difficult. Finding and developing a story about a problem is time-consuming. One of the interviewees, a communicator with a professional background in journalism, claims that it is easier to report on problems when writing newspaper articles than when working as a communicator producing content for an organization, not least since it is easier to simplify or ignore nuances when reporting from the outside:

There are many reporters who don't want things to be too complex because it's hard to write a good headline. But if you work for an organization, you know that it is always more complex than you might want it to be. That's often the case, there are lots of gray areas, and "on the one hand, but on the other hand." And such articles are quite difficult to write. (interview F, April 3, 2018)

One way to construct a positive framing is to give priority to the positive content in articles that contain issues involving both good and bad aspects. For example, the good aspects are often given a prominent position and also more space than the negative aspects. Another way is to use positive news angles even when writing about problematic issues. An illustrative example is an article about supply staff in health care. Although the article begins by declaring that "the costs for supply staff are rising in VGR," the headline exudes hope and inspires confidence: "Work to Cut Health Care Supply Staff Intensifies." Another frequently used (and related) strategy is to not write about organizational problems without also presenting a solution. One interviewee, a VGRfokus editor, states that:

I wouldn't write anything that might harm VGR. [But] I can justify voicing criticism of VGR because it means that there are things we can improve. I have no problem reporting what isn't going well if we also highlight what we are doing to make it work better. But I wouldn't do anything that harms the organization. (Interview H, September 6, 2019)

Clearly, specific strategies are used to write about problems for which VGR could be held responsible. Writing about problems that are not caused by VGR, such as infectious diseases or the annual tick invasion, appears to be easier. Problems sometimes also even appear to be used as opportunities to show that VGR takes responsibility and provides security, protection, and help for its citizens. One prominent example is a number of articles about an outbreak of measles. An infectious diseasein this case a rather severe one that spreads easilyis, of course, in itself something very negative. At the same time, VGR cannot be blamed for the outbreak, and the severe consequences of such a disease can provide opportunities to show that VGR takes responsibility and is an organization to be trusted. For example, one of 
the articles published in VGRfokus during the measles outbreak reports an efficient information service, which is said to have made citizens feel secure and safe during the outbreak. Another article reports that employees worked day and night when the infection spread among patients in a hospital and were thereby able to stop the chain of infection. The positive tone in several of the articles published in connection with the measles outbreak is also visible in explicit assurances that there is no need for the public to worry as VGR takes the outbreak seriously and has it under control since the infection tracing (done by VGR) has been successful.

\subsection{The Human Face: Managers Dominate the Content}

Personification is a key storytelling technique in journalism, often discussed in terms of human interest. The underlying logic is simple: Stories with a human touch tend to attract attention. Our analysis of the content in VGRfokus shows that it is characterized by a high degree of personification; humans are quoted in as many as 94 percent of the articles. Further, in the absolute majority of the analyzed articles (90 percent)-a single actor is the most prominent in terms of number and placements of quotations (e.g., if quoted already in the preamble of the article) as well as photos. As main actors and speakers, these prominent actors are able to partially frame the content of the articles. At the same time, the main actors can also "be used by the writers" to frame the content. Because of this, and also for other reasons (not least questions of representation), it is crucial who is given space in the articles.

In the launching text, the communications director wrote that VGRfokus would "give a voice to all parties involved and provide a context that editorial offices today are not able to do to a sufficient degree" (Lagersten, 2017). This statement corresponds to the above-mentioned ambition to give "a balanced picture by...making room for diverging perspectives when different opinions exist" (VGR, 2017, p. 3). One way to realize such an endeavor is to let different voices be heard.

During our observations, it became obvious that the staff behind VGRfokus were making efforts to give voice to people other than those high up in the VGR hierarchy. For example, during one editorial meeting that took place during the Coronavirus pandemic, the idea arose of producing and publishing an article about employees who had either changed their workplace and work tasks within VGR or left their previous jobs outside VGR in order to help Coronavirus patients and at the same time relieve the heavily burdened health care staff in the intensive care units in the region (editorial meeting, May 5, 2020). The idea was received positively by all the participants, who engaged in a lively discussion to identify appropriate interview persons in different parts of the organization.

Nonetheless, the part of our analysis that focuses on the main actors' institutional roles shows that the actual content of VGRfokus is dominated by managers-and to an even higher degree, it is dominated by organizational members (i.e., persons employed by VGR). The main actor is most frequently a VGR civil servant (77 percent). This category consists of a mix of managers, employees responsible for a specific project or subject area, experts (mainly specialist physicians), and other employees. External actors, i.e., actors not employed by VGR, are placed in the spotlight significantly less often, altogether in 19 percent of the analyzed articles. The main actors in this category represent patients, citizens, and others (e.g., researchers and entrepreneurs). It might not be surprising that the voices heard in and through VGRfokus come mainly from within the organization. However inevitable, it still delimits the perspectives presented through the channel; after all, the vast majority of parties involved in VGR's activities are inhabitants of the region.

The main actors representing VGR are most likely to be a manager, such as operations manager, head of a unit, or human resource manager. Altogether, managers make up half of the main actors representing VGR. In other words, it is mainly the managers-the people in charge, with positions at the top of the organizational hierarchy-who personify the vast organization that is VGR. Often the managers comment on an event, something that has changed in the organization, or a new product or service. Ordinary employees-without a specific position such as project leader and without responsibility for a specific initiative or event-only make up 17 percent of the main actors representing VGR.

Like VGRfokus, legacy media tend to stress the importance of letting different voices be heard-and the outcome is similar: People in high positions, such as managers, tend to be overrepresented. A critical difference between legacy media and VGRfokus, however, is that the managers given a voice in VGRfokus represent the organization that operates the communication channel. Further, individuals interviewed in VGRfokus rarely seem to be faced with critical questions, contrary to what is often the case in legacy media (e.g., Djerf-Pierre et al., 2013). Most often, the voices in the articles (are allowed to) articulate something positive that has happened or is expected to happen, including announcements of new initiatives or events. The human face of VGR tends to be a happy, optimistic face.

According to previous research, the focus on human beings tends to lead towards individualization of issues in focus at the expense of more structural and complex phenomena that are not as easy to transform into a short piece of text that arouses interest (Figenschou \& Thorbjörnsrud, 2018; Rehnberg, 2014), something also noted in VGRfokus. For example, in an article reporting on the long waiting times for prostate cancer test results, the only patient who appears in the text belongs to the small and deviant group of people lucky enough to have received the result in time. Simultaneously, the picture is more complex since managers make up the largest group of main actors in the VGRfokus material. In many of the 
articles where managers appear, they fulfill the rhetorical function of representing the organization rather than themselves as individuals. In light of this, it could be claimed that personification in the VGRfokus material often does not mean individualization.

\section{Discussion: Newsworthiness as a Governing Principle in Line With Bureaucratic and Market Values}

In this section, we elaborate further on the ideas of newsworthiness, suggesting that these ideas make up a certain logic of appropriateness in public sector media work, justifying and legitimizing both bureaucratic values (prescribing civic information) and market values (prescribing branding). We argue that ideas of newsworthiness may tone down or even hide conflicts and tensions between the two values of bureaucracy and market, as otherwise often manifested in public sector communication work. This means that previously identified conflicts-such as conflicts between transparency and inconsistency (Fredriksson \& Edwards, 2019) as well as between coherency and value contradictions (Blomgren et al., 2015)-may seem to be resolved, or may at least appear less disturbing when the communication work builds on, and is justified with the help of, ideas about newsworthiness. These ideas may therefore be rather powerful means in shaping what is considered appropriate (March \& Olsen, 2991) to turn into public news stories, whose voices are being heard and in what ways. Below we elaborate on this argument.

First, the pursuit of turning content into news items reflects ambitions to attract attention and also to reach out through legacy media, as journalists are one of VGRfokus' target groups. These ambitions can easily be interpreted in terms of both civic information and branding activities. VGRfokus is motivated and justified mainly as a way to better reach out to the inhabitants with information about the county council. Topical articles that actively aim to attract readership can be argued as one way to fulfill bureaucratic ambitions to make civic information accessible. At the same time, needless to say, good news about VGR constructs a favorable image of the organization. When VGR is mentioned in articles about, say, sustainable fashion, or portrayed as a provider of advanced health care or as a forerunner in the use of new technology, VGR is constructed as an active, responsible, modern actor-very much in line with ideals of market values and strategic communication. This is in line with previous studies (e.g., Figenschou \& Thorbjörnsrud, 2015) showing that the news format reinforces stories about single events and issues-one at a time-rather than developing broader and more complex stories about challenges and developments in the region. While the ambition to inform inhabitants in the region may be achieved when ideas of newsworthiness govern the communication work, certain aspects will be highlighted in favor of others when information is communicated as news.
What is more, the mere existence of VGRfokus is also image-creating: The fact that VGR has launched and runs a "news channel" characterized by journalistic traits signals values such as being modern and being a forerunner, and it aligns with new trends and innovations. Engaging in media work is therefore in itself something to tell an audience about (representatives of VGRfokus have been invited to speak at conferences on public sector communication), and it adds to the overall image of a modern county council. In other words, engaging in media work might be not only a means to select, produce, and distribute information in an attractive way but also a goal in itself.

Our second elaboration concerns how ideas of newsworthiness justify favoring positive content over negative and, in line with this, positive framings. The aim with VGRfokus, as stated in official documents and in our interviews, is to publish news that not only calls attention to positive issues but also highlights those that are problematic and conflict-oriented. This is very much in line with fulfilling the task of being open and transparent (here understood as bureaucratic values). At the same time, one of the documents also expresses the ambition to "place VGR on the national map" as well as to use VGRfokus to provide the organization with a "voice in the public debate" (VGR, 2017, p. 2). VGRfokus is thus also expected to be a channel for branding communication. And while the aim to inform citizens can arguably be achieved through all kinds of information, whether positive or negative content, branding activities are not easily done through negative and problemoriented stories. Further, the ambition to inform citizens about what is going on in a region does not stipulate any specific tone, whether positive or negative; rather, information can easily be conveyed in a neutral, even dry, format. However, the basic idea of strategic communication and branding is to shape the information in formats that increase the opportunities to reach out and influence people's opinions and evaluations of phenomena. One possible interpretation would therefore be that traditional bureaucratic values of informing citizens would allow for different kinds of stories in terms of tone, while branding activities would favor content that is either perceived as positive (as exemplified in the previous section) or can be framed positively, that is to say, presented in a way that emphasizes positive aspects (although negative aspects might also exist) and discussed in a positive tone.

Third, bureaucratic values do not necessarily imply that human voices are used in attempts to inform citizens. It could even be argued that the dry format without a human touch is preferable since a focus on individuals might jeopardize the pursuit of factuality, impartiality, and equal treatment. On the other hand, in order to be open and transparent and to protect democratic ideals in the public sector, a human focus may offer opportunities for employees in different parts of the organization to have a voice and to be heard-provided that others than managers are also allowed to speak. Further, personified 
content might be more easily comprehended than depersonalized information. The situation concerning market values is less complex: Content that is easily spread and awakens interest is prioritized in branding. The human face is a critical tool in developing such stories. In this way, while ideas on newsworthiness and market values tend to go hand in hand and support one another in the creation of personified content, the situation is more ambiguous concerning bureaucratic values.

\section{Conclusions}

Our analysis shows that journalistic methods and formats fulfill multiple functions in VGR's communication. Our analysis has opened the box and shed light on how content is produced internally by a public agency. Ideas on newsworthiness, which we here understand as a form of logic of appropriateness, become governing principles for what is considered to be appropriate topics to tell about and how. The civil servants' interpretations of newsworthiness tend to motivate and favor stories that are short, likely to arouse interest, and concern something that is current. Further, the news format is used in a way that tends to favor positive aspects over negative and to give most space to managers.

As we have illustrated, ideas of newsworthiness make certain types of news content appear more appropriate than others. The image of VGR that is constructed is very much that of a safe, modern, and solutionfocused organization with responsible employees and active, engaged, and influential managers. This is an image that goes hand in hand with a coherent and agentic organization, i.e., underlying norms of strategic communication and the business firm (here understood as market values). However, as stressed both by interviewees and in official documents, the articles in VGRfokus are not to cover only positive aspects. In order to be trustworthy and fulfill ambitions of openness and transparency (bureaucratic values), problems and conflict areas are also to be included. Our analysis shows that when problems are included, they are combined with something positive-the problem needs to be positively packaged in some way with a solution in sight or ongoing improvement work. More neutral, informative, dry content does not qualify as news per se. That kind of information, if it cannot be presented as newsworthy but must be published, is dispatched to VGR's traditional website-a site that can be understood to be rooted in traditional bureaucratic values stressing the obligation to make information available to citizens.

The news format is something that civil servants at VGR describe and justify as a tool that can be used mainly in order to fulfill the democratic mission to spread civic information to citizens, but also in branding. Media work-and the establishment of newsworthiness as a logic of appropriateness-may be seen as a self-evident and value-free additional technique to employ to package information and to create visibility and credibility.
However, while journalistic methods and formats are generally described by our interviewees as simply a means for reaching out-not least in order to fulfill a democratic mission in terms of informing citizens about what is going on-they are formative. They govern the actual communication activities, as they justify and legitimize what information is appropriate to turn into news, how it is presented, and by whom it is promoted. From such a perspective, ideas of newsworthiness and media work might be a rather powerful means to present an organization in certain ways, for example as innovative, modern, and responsible, and to create an image of a coherent and agentic organization. Simultaneously, the same ideas of newsworthiness justify and legitimize opting out from other topics, for example problems without solutions or any initiated action plan and issues that are difficult to turn into attractive stories with a human face.

Finally, it is worth remembering that a case study design-focusing only on one particular news channel in our analysis-obviously has its limitations. Although we take as a point of departure for our analysis that news production and the engagement in media work can be understood as a trend in the public sector, our single example of VGRfokus does not give us sufficient insights to develop what such a trend may entail and how it may influence public sector communication more broadly. Therefore, we see our study as a starting point in a series of investigations to come. As is evident, media work is not to be seen nowadays as a practice to be performed only by media organizations, but as a type of work in which we can expect different kinds of organizations to engage to varying degrees. Accordingly, we argue that the democratic mission of public agencies makes them particularly important to examine further in order to fully understand the role and impact that media work may have.

\section{Acknowledgments}

The authors would like to thank Anne-Marie and Gustaf Anders Foundation for media research and Åke Wibergs Stiftelse for funding our study. In addition, the authors are grateful for constructive and helpful comments by two anonymous reviewers as well as the academic editors.

\section{Conflict of Interests}

The authors declare no conflict of interest.

\section{References}

Aare, C. (2021). Reportaget som berättelse [The reportage as narrative] [Unpublished doctoral thesis, Stockholm University]. DiVA Portal. https://su. diva-portal.org/smash/get/diva2:1523808/ FULLTEXT01.pdf

Ahva, L., van Dalen, A., Hovden, J. F., Kolbeins, G. H., 
Löfgren Nilsson, M., Morten, S., \& Väliverronen, J. (2017). A welfare state of mind? Nordic journalists' conception of their role and autonomy in international context. Journalism Studies, 18(5), 595-613.

Blomgren, M., Hedmo, T., \& Waks, C. (2015). Struggles behind the scenes: Reputation management in Swedish hospitals. In A. Waeraas \& M. Maor (Eds.), Organizational reputation in the public sector (pp. 163-184). Routledge.

Byrkjeflot, H. (2015). Driving forces, critique, and paradoxes of reputation management in public organizations. In A. Waeraas \& M. Maor (Eds.), Organizational reputation in the public sector (pp. 54-74). Routledge.

Christensen, T., Laegreid, P., Roness, P. G., \& Rövik, K. A. (2007). Organization theory and the public sector. Routledge.

Czarniawska, B. (1998). A narrative approach to organization studies. SAGE.

Deuze, M. (2005). What is journalism? Professional identity and ideology of journalists reconsidered. Journalism, 6(4), 442-464.

Deuze, M. (2009). Media industries, work and life. European Journal of Communication, 24(4), 467-480.

Djerf-Pierre, M., Ekström, M., \& Johansson, B. (2013). Policy failure or moral scandal? Political accountability, journalism and new public management. Media, Culture \& Society, 35(8), 960-976.

Ekengren, S. (2018). Följarna först: Redaktionell metod för kommunikatörer [The followers first: Editorial method for communication specialists]. Liber.

Figenschou, T. U., Fredriksson, M., Kolltveit, K., \& Pallas, J. (2021). Public bureaucracies. In E. Skogerb $\varnothing, \varnothing$. Ihlen, N. N. Kristensen, \& L. Nord (Eds.), Power, communication, and politics in the Nordic countries (pp. 325-345). Nordicom.

Figenschou, T. U., \& Thorbjörnsrud, K. (2015). Backstage media-government negotiations: The failures and success of a government pitch. International Journal of Communication, 9, 1957-1965.

Figenschou, T. U., \& Thorbjörnsrud, K. (2018). Mediated agency, blame avoidance, and institutional responsibility: Government communication in a personalized media landscape. Scandinavian Political Studies, 41(2), 210-232.

Fredriksson, M., \& Edwards, L. (2019). Communicating under the regimes of divergent ideas: How public agencies in Sweden manage tensions between transparency and consistency. Management Communication Quarterly, 33(4), 548-580.

Fredriksson, M., \& Pallas, J. (2016). Diverging principles for strategic communication in government agencies. International Journal of Strategic Communication, 10(3), 153-164.

Grafström, M., \& Rehnberg, H. S. (2019). Public organizations as news producers. Nordicom Review, 40(2), 85-100.

Harcup, T., \& O'Neill, D. (2017). What is news? Journal- ism Studies, 18(12), 1470-1488.

Heide, M., \& Simonsson, C. (2015). Struggling with internal crisis communication. Public Relations Inquiry, 4(2), 223-255.

Hood, C. (1991). A public management for all seasons? Public Administration, 69(1), 3-19.

Jacobs, S., \& Wonneberger, A. (2019). Dealing with increasing complexity: Media orientations of communication managers in public sector organizations. International Journal of Communication, 13, 918-937.

Kalix bygger nyhetsredaktion [Kalix starts a newsroom]. (2014, April 17). Dagens Opinion.

Kolltveit, K., \& Figenschou, T. U. (2020). Communication experts in public bureaucracies: A new type of civil servants? Norsk statsvitenskapelig tidsskrift, 36(2), 102-119.

Kommun startar egen "nyhetsförmedling" [Municipality starts its own news "agency"]. (2019, January 29). Journalisten.

Lagersten, E. (2017, November 12). Ledare: Därför drar VGR igång en egen nyhetssajt [Why VGR starts its own news site]. VGRfokus. https://vgrfokus.se/2017/ 11/ledare-darfor-drar-vgr-igang-egen-nyhetssajt

March, J. G., \& Olsen, J. P. (2011). The logic of appropriateness. In R. E. Goodin (Ed.), The Oxford handbook of political science (pp. 478-500). Oxford University Press.

Region Västra Götaland. (2017). Riktlinje: Digital nyhetskanal VGRfokus [Guideline: Digital news channel VGRfokus]. Västra Götalandsregionen.

Rehnberg, H. S. (2014). Organisationer berättar: Narrativitet som resurs $i$ strategisk kommunikation [When organizations tell stories: Narrativity as a resource in strategic communication] [Unpublished doctoral thesis, Uppsala University]. DiVA portal. http://uu.diva-portal.org/smash/get/diva2:758669/ FULLTEXT02.pdf

Rehnberg, H. S., \& Grafström, M. (2021). Using counternarrative to defend a master narrative: Discursive struggles reorganizing the media landscape. In K. Luego \& M. Wolff Lundholt (Eds.), Routledge handbook of counter-narratives (pp. 209-222). Routledge.

Schudson, M. (2003). The sociology of news. W. W. Norton.

Strömbäck, J. (2019). Journalistikens nyhetsurval och nyhetsvärderingar [News selection and news evaluation in journalism]. In M. Karlsson \& J. Strömbäck (Eds), Handbok i journalistikforskning [Handbook in journalism research] (pp. 171-181). Studentlitteratur.

Strömbäck, J., Karlsson, M., \& Hopmann, D. N. (2012). Determinants of news content: Comparing journalists' perceptions of the normative and actual impact of different event properties when deciding what's news. Journalism Studies, 13(5), 718-728. https:// doi.org/10.1080/1461670X.2012.664321

Sundling, J. (2015, June 11). Kommunerna tar över 
nyhetsmatchen [The municipalities are taking over the news match]. Dagens Samhälle. www. dagenssamhalle.se/styrning-och-beslut/kommun politik/kommunerna-tar-over-nyhetsmatchen

Thorbjørnsrud, K., \& Ytreberg, E. (2020). A human interest economy: The strategic value of turning ordinary people into exemplars in the news media. Journalism
Studies, 21(8), 1093-1108.

Wæraas, A. (2008). Can public sector organizations be coherent corporate brands? Marketing Theory, 8(2), 205-221.

Wiik, J. (2008). Identities under construction: Professional journalism in a phase of destabilization. International Review of Sociology, 19(2), 351-365.

\section{About the Authors}

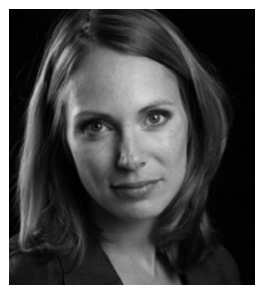

Maria Grafström (PhD) is associate professor of business studies and an organizational scholar at Stockholm Centre for Organizational Research, Stockholm University and Stockholm School of Economics. Her research focuses on the mediatization of organizations and how media participate in creating and circulating ideas and shaping organizational agendas.

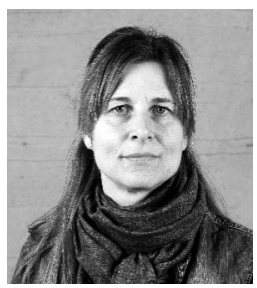

Hanna Sofia Rehnberg (PhD) is a senior lecturer in Swedish at Uppsala University and affiliated to Stockholm Centre for Organizational Research, Stockholm University and Stockholm School of Economics. As a sociolinguist with a professional background as a journalist, she investigates language use in society, focusing on narrativity, journalism, organizational communication, and communication in the asylum process. 